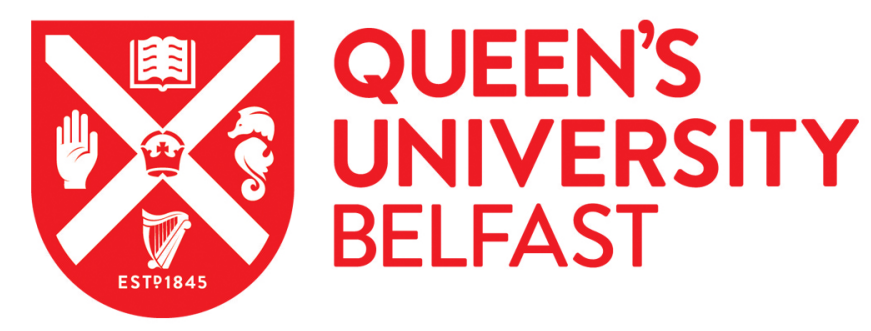

\title{
Influence of presbyopia on smartphone usage among Chinese adults: a population study
}

Wang, C., Wang, X., Jin, L., Tang, B., Zhu, W., Zhang, G., Chen, T., McAneney, H., Kassalow, J., \& Congdon, N. (2019). Influence of presbyopia on smartphone usage among Chinese adults: a population study. Clinical and Experimental Ophthalmology, 47(7), 909-917. https://doi.org/10.1111/ceo.13559

Published in:

Clinical and Experimental Ophthalmology

Document Version:

Peer reviewed version

Queen's University Belfast - Research Portal:

Link to publication record in Queen's University Belfast Research Portal

Publisher rights

Copyright 2019 Wiley. This work is made available online in accordance with the publisher's policies. Please refer to any applicable terms of use of the publisher.

\section{General rights}

Copyright for the publications made accessible via the Queen's University Belfast Research Portal is retained by the author(s) and / or other copyright owners and it is a condition of accessing these publications that users recognise and abide by the legal requirements associated with these rights.

Take down policy

The Research Portal is Queen's institutional repository that provides access to Queen's research output. Every effort has been made to ensure that content in the Research Portal does not infringe any person's rights, or applicable UK laws. If you discover content in the Research Portal that you believe breaches copyright or violates any law, please contact openaccess@qub.ac.uk. 
Original Article - Clinical Science

\title{
Influence of presbyopia on smartphone usage among Chinese adults: a population study
}

\author{
Congyao Wang $\mathrm{MD},{ }^{1}$ Xiuqin Wang $\mathrm{PhD},{ }^{1,2}$ Ling Jin MS, ${ }^{1}$ Bobby Tang MBChB, ${ }^{4}$ Wenhui \\ Zhu MD, ${ }^{1,3}$ Guoshan Zhang MM, ${ }^{1}$ Tingting Chen MD, ${ }^{1,3}$ Helen McAneney MD, ${ }^{4}$ Jordan \\ Kassalow $\mathrm{MD}^{5}$ and Nathan Congdon $\mathrm{MD}^{1,4,6}$
}

${ }^{1}$ State Key Laboratory of Ophthalmology, Zhongshan Ophthalmic Center, Sun Yat-sen University, Guangzhou 510060, China

${ }^{2}$ The Ophthalmology Department, the Hospital of Guangdong Medical University, Zhanjiang, Guangdong Province, China

${ }^{3}$ The Ophthalmology Department, the First Affiliated Hospital of Sun Yat-sen University, Guangzhou, Guangdong Province, China

${ }^{4}$ Centre for Public Health, Queen's University Belfast, Belfast, United Kingdom

${ }^{5}$ Visionspring, New York, USA

${ }^{6}$ Orbis International, New York, USA

Correspondence: Prof. Nathan Congdon, State Key Laboratory of Ophthalmology, Zhongshan Ophthalmic Center, Sun Yat-sen University, Guangzhou 510060, China and Centre for Public Health, Royal Victoria Hospital, Queen's University Belfast, Belfast, 274 Grosvenor Rd, Belfast, BT12 6BA, UK ncongdon1@gmail.com

Short running title: Presbyopia and smartphone usage

This article has been accepted for publication and undergone full peer review but has not been through the copyediting, typesetting, pagination and proofreading process which may lead to differences between this version and the Version of Record. Please cite this article as doi: $10.1111 /$ ceo.13559 
Received 8 December 2018; accepted 25 April 2019

Funding sources / Financial disclosure: Prof Congdon is supported by a Thousand Man Plan grant from the Chinese government and by the Ulverscroft Foundation (UK). The study sponsor played no role in study design and the collection, analysis, and interpretation of data, the writing of the article or the decision to submit it for publication.

Conflict of interest: None 


\section{ABSTRACT}

Importance: Presbyopia, an essentially-universal, age-related loss of the ability to focus un-aided on near objects, is the world's leading cause of visual impairment.

Background: Smartphone use is widespread in China, but little is known about the prevalence, determinants and correction of difficulties with smartphone use in the setting of presbyopia.

Design: Cross-sectional data from a population-based longitudinal cohort study. Participants: 1817 persons aged $\geq 35$ years in Guangzhou, southern China.

Methods: Participants underwent near visual acuity (NVA) testing and completed questionnaires on smartphone usage detailing knowledge of their own presbyopia status, frequency (hours/day) and subjective difficulties with use of mobile and smartphones. Presbyopia was defined as uncorrected bilateral near visual acuity $\leq 6 / 12$ with best-corrected bilateral near visual acuity $>6 / 12$.

Main outcome Measures: Difficulty in smartphone use associated with uncorrected presbyopia.

Results: Among 1427 respondents (78.5\%) undergoing examination, 1191 (83.5\%) completed questionnaires (mean age $52.3 \pm 11.6$ years; $54.9 \%$ women). Among 451 persons (37.8\%) with presbyopia owning smartphones, 290 (64.3\%) reported difficulty using them. Multiple ordinal logistic regression modelling showed difficulty in smartphone use due to presbyopia was associated with higher educational level $(p=0.013)$, worse NVA $(p<0.001)$ and more time spent using smartphones $(p=0.002$ for 1-3 hours/day). Among persons with presbyopia owning smartphones, 353 (78.0\%) said they would pay >US $\$ 15$ (median US $\$ 45$ ) for innovations making smartphone use easier. 
Conclusions and relevance: Difficulty in using smartphones in the presence of presbyopia is common and affected persons are willing to pay for useful solutions to the problem.

Key words: Presbyopia, smartphone, near vision impairment, population study

\section{INTRODUCTION}

Presbyopia, the impairment of near vision in older adults due to the gradual loss of accommodation, currently affects over 1 billion people worldwide. ${ }^{1,2}$ It is estimated that half of affected persons cannot afford corrective spectacles, particularly in under-served regions of low and middle-income countries (LMICs). ${ }^{3}$ A recent multi-country, population-based study showed that over $90 \%$ of near vision impairment was uncorrected in rural areas of LMICs, compared to $40 \%$ in urban areas. ${ }^{4}$ This study also demonstrated a sharp rise in the prevalence of presbyopia during the working years, with the majority over 50 years suffering from correctable near vision impairment (CNVI), and prevalence as high as 50\% among those aged 35-39 in some regions. ${ }^{5}$ Uncorrected presbyopia leads to an estimated global productivity loss of $\$ 25.4$ billion. ${ }^{1}$ Despite this, most research on uncorrected refractive error has focused on impairment of distance vision. While presbyopia may once have been considered less problematic in rural LMIC settings due to lower literacy levels and life expectancy, recent studies have demonstrated a significant impact on quality of life and activities of daily living. ${ }^{6-15}$ A population-based, cross-sectional study in rural China showed that the prevalence of presbyopia increased from $27.6 \%$ at $40-49$ years of age to $81.8 \%$ at $60-69$ years, with only $51.5 \%$ of affected persons reporting spectacle ownership. Major barriers included poor quality of available glasses and lack of awareness of the condition and its treatment. ${ }^{6}$ In addition to low levels of visual functioning, restricted social interaction 
and leisure activities and a diminished sense of accomplishment among those with presbyopia, this group was significantly more likely to experience difficulties with activities of daily living than unaffected persons (94.6 versus $69.3 \%, p<0.001)^{7}$ Uncorrected presbyopia has also been shown to affect quality of life in rural Tanzania, where the large majority of presbyopes ( $94 \%$ ) did not have corrective near vision glasses. ${ }^{8}$ Those with presbyopia were more likely to report difficulty with near-vision tasks such as cooking, threading a needle and sorting grain or rice. Similarly, a study in Nigeria found impairment of near vision to be associated with reduced quality of physical, psychological and social aspects of life. ${ }^{9}$ The most severely-affected functions in those self-reporting near vision impairment were reading, writing, use of mobile phones and threading a needle. ${ }^{10}$ Further studies in India ${ }^{11}$, Zanzibar ${ }^{12}$, Kenya ${ }^{13}$ and Timor-Leste ${ }^{14}$ add to the evidence that near visual impairment is associated with lower quality of life even where the illiteracy rate is high, due to difficulty in managing near tasks of daily living.

The impact of presbyopia has become more pronounced in LMICs due to population aging and technological advancements. ${ }^{15}$ Chief among these is the growing reliance on smartphones. In 2015, the World Bank estimated the number of mobile cellular subscriptions per 100 people to be 98.6 worldwide and 93.2 in China. ${ }^{16}$ Based on the latest Mobility Report from Ericsson, there are currently 3.9 billion smartphone subscriptions worldwide, with that number expected to reach 8.9 billion by 2022 . Subscriptions for smartphones have surpassed those for basic mobile phones, with smartphones now accounting for close to $80 \%$ of all mobile phones sold. ${ }^{17}$ Few studies have assessed the influence of presbyopia on the use of basic mobile phones in LMICs, ${ }^{10,18}$ and existing reports have neither assessed the degree of presbyopia in population-based samples, nor have they examined determinants of selfreported difficulty with smartphone use. We surveyed a prospectively-followed, 
population-based cohort of older Chinese persons, drawn from a multi-country study of presbyopia, ${ }^{4,19,21}$ on their attitudes towards and use of smartphones. The aim of the current study is to define the prevalence and determinants of self-reported difficulty with smartphone use in an older LMIC population, while assessing the efficacy of various behavior modifications in reducing difficulty of use, and willingness of users to pay for technological solutions to the problem.

\section{METHODS}

Data were collected in a population-based, longitudinal cohort study from March to April 2014. All participants in this study were derived from a multi-site study of presbyopia, and were adults aged $\geq 35$ years at the time of the initial examination in 2008-2009, selected by random cluster sampling from the Yuexiu District of Guangzhou, Southern China. Details of the study methodology have been previously reported. ${ }^{4}$ In brief, 2284 persons were counted by trained enumerators through door-to-door visits in 20082009. Among the 1817 (79.6\%) participants who attended baseline examinations, 1595 (87.8\%) took part in the follow-up examination in 2010, and 1427 (78.5\%) in 2014, after their identity and basic demographic information (name, age, gender) was confirmed and informed consent was obtained.

The basic study protocol, provided originally by the World Health Organization Secretariat Committee on Research Involving Human Subjects, and arrangements for additional data-gathering on smartphone use, were reviewed and approved in full by the Ethics Committee of the Zhongshan Ophthalmic Center, Sun Yat-sen University, Guangzhou, China. Written informed consent was given by all participants, and the principles of the Declaration of Helsinki were followed throughout. 


\subsection{Examination Procedures}

All examinations took place at local clinics and other community facilities, and baseline examination information was not provided to study personnel carrying out the presbyopia sub-study. Binocular near visual acuity (NVA), with and without presenting near correction, was measured at $40 \mathrm{~cm}$ using a logMAR near vision tumbling $E$ chart (Precision Vision, La Salle, Illinois, USA) in a bright room, and recorded as the smallest line read with one or no errors. Participants with uncorrected binocular NVA $\leq 6 / 12$ were tested with successively higher-powered plus sphere lenses to measure best-corrected binocular NVA. Presenting NVA could not routinely be assessed due to the small proportion of participants who brought their reading glasses, despite being asked in advance to do so.

\subsection{Definitions}

Functional presbyopia is an age-related near-vision impairment. CNVI was defined as uncorrected bilateral near visual acuity $\leq 6 / 12$ with best-corrected bilateral near visual acuity $>6 / 12$. Only persons with bilateral NVA $\leq 6 / 19$ improving to $>6 / 12$ with refraction were regarded as requiring near correction. The definition of smartphone used in the current study was a handheld device having an independent operating system, the potential to use programs made available by third-party service providers, such as software, games and navigation, and wireless access to mobile communication networks.

\subsection{Questionnaires}

The questionnaire used in the current study was administered in person or by telephone in Mandarin/Cantonese by trained interviewers in the subject's home or at local clinics. It contained 37 items arranged in sections: (1) Knowledge of the respondent about 
his/her own presbyopia status; (2) Characteristics of mobile and smartphone use; (3) Self-reported difficulties with smartphone use due to presbyopia ( $1=$ Absolutely no difficulty to $5=$ Very difficult) ; (4) Potential means to address these barriers and willingness to pay for effective solutions.

\subsection{Statistical Methods}

Demographic characteristics of subjects were described as mean (SD, standard deviation) or median (IQR, Interquartile range) for continuous data and frequency (proportion) for categorical variables. Participants completing and not completing questionnaires were compared on demographic characteristics by conducting a twosample $t$ test for age, Cochran-Armitage test for uncorrected bilateral NVA and Chisquared test for the other variables. Data on trends in self-reported ownership and use of presbyopic glasses and smartphones among participants completing questionnaires was presented as frequency (proportion). The data for the variable "How much would you pay for a smartphone that could automatically adjust the screen to allow near viewing even with presbyopia?" was collected as a categorical variable with 6 levels (RMB 100 to 2000, based on annual expenditures for communication and electronic products by residents in the region in 2014), and the median and IQR were calculated using the mean of the minimum and maximum values of the range at each level. We performed ordinal logistic regression modeling on the primary outcome, difficulty in smartphone use due to CNVI without presbyopic glasses, and logistic regression modeling to detect potential predictors of presbyopic spectacle wear among all participants. Variables with $\mathrm{P}<0.20$ in the simple regressions were included in the multiple regression model. All statistical analyses were performed using a commercially available software package (Stata 13.1, StataCorp, College Station TX, USA). 


\section{RESULTS}

Among the 1817 participants who were previously examined at the Yuexiu site, 1427 (78.5\%) participated in the follow up examination and $1191(83.5 \%)$ completed the questionnaire. Comparing baseline characteristics of those who completed the questionnaire versus those who did not, there were no significant differences in terms of age, gender, presenting distance visual acuity, and levels of corrected and uncorrected near vision impairment. However, those who completed questionnaires had a lower level of education, with $37.6 \%(n=448)$ not having finished high school, compared to $26.8 \%(n=55)$ in those who did not complete questionnaires $(p=0.005)$. (Table 1)

Among those who completed the questionnaire, (mean age 52.6, standard deviation 11.5 years $), 70.1 \%(n=830$, labeled $D$ in figure 1$)$ had CNVI, $66.2 \%(n=782)$ had reading glasses and $55.0 \%(n=654$, labeled $A$ in figure 1$)$ owned smartphones. Among persons who owned reading glasses, $90.9 \%(n=686$, labeled $C$ in figure 1$)$ reported wearing them for at least some tiame every day, and smartphones were owned by $69.1 \%$ ( $n=451$, labeled B in figure 1$)$ of those diagnosed with CNVI.

Figure 1: Recruitment and characteristics of participants in the study 
Table 1: Demographic characteristics of subjects completing and not completing questionnaires in 2014. Values are $n$ (\%) unless stated otherwise

\begin{tabular}{|c|c|c|c|c|c|}
\hline Characteristic & All & $\begin{array}{c}\text { Completing } \\
\text { Questionnaire }\end{array}$ & $\begin{array}{c}\text { Not } \\
\text { Completing } \\
\text { Questionnaire }\end{array}$ & $\begin{array}{c}\text { P-value } \\
\text { (Completing } \\
\text { versus Not } \\
\text { Completing) }+\end{array}$ & $\begin{array}{c}\text { Missing } \\
\text { data }\end{array}$ \\
\hline Total & 1427 & $1191(83.5 \%)$ & $236(16.5 \%)$ & 1 & / \\
\hline Age, mean (SD), years & $52.3(11.6)$ & $52.5(11.5)$ & $51.1(11.8)$ & 0.09 & $0(0.00)$ \\
\hline Female sex & $784(54.9)$ & $662(55.6)$ & $122(51.7)$ & 0.27 & $0(0.00)$ \\
\hline Education & & & & 0.005 & $15(1.05)$ \\
\hline Less than high school & $508(36.0)$ & $447(37.5)$ & $61(27.6)$ & & \\
\hline High school or above & $904(64.0)$ & $744(62.5)$ & $160(72.4)$ & & \\
\hline Correctable Near Vision Impairment* & $978(69.9)$ & $830(70.1)$ & $148(68.8)$ & 0.71 & $28(1.96)$ \\
\hline Uncorrected bilateral near visual acuity & & & & 0.07 & $23(1.61)$ \\
\hline$>20 / 40$ & $267(19.0)$ & $226(19.0)$ & $41(19.0)$ & & \\
\hline$>20 / 63$ to $\leq 20 / 40$ & $345(24.6)$ & $279(23.5)$ & $66(30.6)$ & & \\
\hline$\leq 20 / 63$ & $792(56.4)$ & $683(57.5)$ & $109(50.5)$ & & \\
\hline Best-corrected bilateral near visual acuity & & & & 0.74 & $9(0.63)$ \\
\hline
\end{tabular}




\begin{tabular}{|c|c|c|c|c|c|}
\hline$>20 / 40$ & $1262(89.0)$ & $1057(89.1)$ & $205(88.4)$ & & \\
\hline$\leq 20 / 40$ & $156(11.0)$ & $129(10.9)$ & $27(11.6)$ & & \\
\hline Presenting bilateral distance vision & & & & 0.57 & $21(1.47)$ \\
\hline $\begin{array}{l}>20 / 40 \\
\leq 20 / 40\end{array}$ & $\begin{array}{c}1050(74.7) \\
356(25.3)\end{array}$ & $\begin{array}{l}892(75.0) \\
298(25.0)\end{array}$ & $\begin{array}{c}158(73.2) \\
58(26.8)\end{array}$ & & \\
\hline
\end{tabular}

SD: Standard deviation

† Two-sample $t$ test was used for the comparison on age, Cochran-Armitage test for uncorrected bilateral NVA and the Chi-squared test for the other variables.

* Correctable near vision impairment was defined as uncorrected bilateral near visual acuity $\leq 20 / 40$ with best-corrected bilateral near visual acuity $>20 / 40$. 
In the group with CNVI who owned smartphones (B), 68.1\% $(n=290)$ reported difficulty in using them due to problems with near vision. The most commonly-reported coping strategy was the use of presbyopic glasses $(73.7 \%, n=213)$, whereas $13.2 \%(n=38)$ had no particular strategy and only $2.42 \%(n=7)$ used screen adjustments to manage problems with using their smartphone due to poor near vision. (Table 2) Among persons who completed the questionnaire, 37.9\% $(n=452)$ were interested in a smartphone feature to remediate presbyopia with screen adjustments and $78.0 \%$ ( $n=353$ ) of these persons were willing to pay $\geq \$ 15$ for this feature. (Median $\$ 45$, IQR \$45-187). (Table 2)

Table 2: Trends in self-reported ownership and use of presbyopic glasses and smart phones among subjects completing questionnaires ( $n=1191$, unless an otherwise noted subgroup see Figure 1)

\begin{tabular}{lcc}
\hline & $\mathbf{n}(\%)$ & Missing data \\
\hline $\begin{array}{l}\text { Own reading glasses } \\
\text { Time wearing presbyopic glasses among those }\end{array}$ & $781 / 1181(66.1)$ & $26(3.33)$ \\
owning, hours/day (n=781) & & \\
$\quad 0$ & $69 / 755(9.14)$ & \\
$\leq 1$ & $360 / 755(47.7)$ & \\
$>1$ to $\leq 3$ & $212 / 755(28.1)$ & \\
$>3$ & $114 / 755(15.1)$ & $2(0.17)$ \\
Own smart phone * (labeled A in Figure 1) & $654 / 1189(55.0)$ & $4(0.34)$ \\
Own standard mobile phone & $436 / 1187(36.7)$ & \\
(without browsing or other computer functions)* & & \\
Time using smart phone among those owning, & & \\
hours/day (n=654 labeled A in Figure 1) & & \\
$\quad \leq 1$ & $294 / 628(46.8)$ & \\
$\quad>1$ to $\leq 3$ & $211 / 628(33.6)$ & \\
$\quad>3$ & $123 / 628(19.6)$ & \\
Difficulty using smart phone due to correctable & & \\
near vision impairment (n=451 labeled B in & & \\
Figure 1)† & &
\end{tabular}


Absolutely no difficulty

Not difficult

Not sure

Difficult

Very difficult

Coping strategies used by those reporting

difficulty due to correctable near vision

impairment $(n=290) \neq$

Use presbyopic glasses

Use bifocals

Remove distance glasses

No particular strategy

Adjust phone: Bigger characters, Brighter Screen,

How well does the solution work? $(n=289) \neq$

Very effective

Effective

Moderately effective

Not effective

Completely ineffective

Would you be interested in a mobile phone which can automatically adjust the screen to accommodate presbyopia?

Extremely not interested

Not interested

Neutral

Interested

Very interested

How much would you pay for the feature (US\$)

$(n=452) \S$

$<15$

15-75

$76-150$

$151-225$

$226-300$
$49 / 426(11.5)$

$75 / 426(17.6)$

$12 / 426(2.82)$

$196 / 426(46.0)$

$94 / 426$ (22.1)

$1(0.34)$

$213 / 289$ (73.7)

$10 / 289$ (3.46)

21/289 (7.27)

38/289 (13.2)

$7 / 289$ (2.42)

$38(13.2)$

$147 / 251$ (58.6)

$102 / 251(40.6)$

2/251 (0.80)

$0 / 251(0.00)$

$0 / 251(0.00)$

59 (4.95)

286/1132 (25.3)

314/1132 (27.7)

$81 / 1132$ (7.16)

333/1132 (29.4)

118/1132 (10.4)

$2(0.44)$

$97 / 450(21.6)$

$146 / 450$ (32.3)

$70 / 450$ (15.6)

$57 / 450$ (12.7)

$32 / 450$ (7.13) 
*Some subjects reported owning both standard and smart mobile phones

tThe denominator included those among the 654 smart phone owners who also had correctable near vision impairment.

\#This denominator includes only those persons having mobile phones and correctable near vision impairment, and who reported mobile phone use to be "Difficult" or "Very difficult.

$\S$ The feature was that a mobile phone can automatically adjust the screen to accommodate presbyopia. The denominator includes people who reported interest in this feature.

In multiple ordinal logistic regression analysis, predictors of having difficulty in smartphone usage due to uncorrected near vision impairment included NVA $\leq 20 / 63$ (OR 2.59; 95\% CI 1.73, 3.87; $\mathrm{p}<0.001$ ), higher education level (OR 1.72; 95\% CI 1.12, 2.64; $p=0.013)$ and spending more time in daily smartphone usage (1-3 hours/day OR 1.94; $95 \%$ CI 1.27, 2.98; $\mathrm{p}=0.002$; >3 hours/day OR 2.21; 95\% CI 1.27, 3.86; $\mathrm{p}=0.005$ ), after adjusting for age, gender, best-corrected near visual. (Table 3 )

Table 3: Ordinal logistic regression model of potential predictors of difficulty in smart phone use due to correctable near vision impairment without presbyopic glasses (Difficulty was coded as 1 to $5: 1=$ Absolutely no difficulty, $5=$ =Very difficult) ( $n=451$, labeled $B$ in figure 1) 


\begin{tabular}{|c|c|c|c|c|}
\hline \multirow[t]{2}{*}{ Variables } & \multicolumn{2}{|c|}{$\begin{array}{c}\text { Simple } \\
\text { ordinal logistic } \\
\text { regression }\end{array}$} & \multicolumn{2}{|c|}{$\begin{array}{c}\text { Multiple } \\
\text { ordinal logistic regression* } \\
(\mathrm{n}=413)\end{array}$} \\
\hline & OR (95\% CI) & P-value & OR (95\% CI) & P-value \\
\hline Age (y) & $1.02(0.99,1.05)$ & 0.08 & $1.01(0.98,1.03)$ & 0.70 \\
\hline Female sex & $1.47(1.03,2.09)$ & 0.03 & $1.36(0.94,1.96)$ & 0.10 \\
\hline \multicolumn{5}{|l|}{ Education } \\
\hline Less than high school & Reference & & Reference & \\
\hline High school or above & $1.76(1.17,2.65)$ & 0.007 & $1.72(1.12,2.64)$ & 0.013 \\
\hline \multicolumn{5}{|l|}{ Monthly income, US\$ } \\
\hline$<300$ & Reference & & & \\
\hline$\geq 300$ to $<600$ & $1.14(0.69,1.86)$ & 0.61 & & \\
\hline$\geq 600$ to $<900$ & $1.08(0.59,1.98)$ & 0.80 & & \\
\hline$\geq 900$ & $1.18(0.64,2.17)$ & 0.60 & & \\
\hline \multicolumn{5}{|c|}{$\begin{array}{l}\text { Time using smart phone } \\
\text { among those owning, } \\
\text { hours/day }(n=654)\end{array}$} \\
\hline$\leq 1$ & Reference & & Reference & \\
\hline$>1$ to $\leq 3$ & $1.34(0.90,2.00)$ & 0.15 & $1.94(1.27,2.98)$ & 0.002 \\
\hline$>3$ & $1.79(1.04,3.08)$ & 0.04 & $2.21(1.27,3.86)$ & 0.005 \\
\hline \multicolumn{5}{|l|}{$\begin{array}{l}\text { Uncorrected bilateral } \\
\text { near visual acuity } \dagger\end{array}$} \\
\hline$>20 / 63$ to $\leq 20 / 40$ & Reference & & Reference & \\
\hline$\leq 20 / 63$ & $3.18(2.18,4.63)$ & $<0.001$ & $2.59(1.73,3.87)$ & $<0.001$ \\
\hline \multicolumn{5}{|l|}{$\begin{array}{l}\text { Presenting bilateral } \\
\text { distance vision acuity }\end{array}$} \\
\hline$>20 / 40$ & Reference & & & \\
\hline
\end{tabular}

This article is protected by copyright. All rights reserved. 
$\leq 20 / 40$

Having reading glasses
$0.93(0.53,1.65)$

$4.19(2.67,6.57) \quad<0.001$

† All 426 persons with correctable near vision impairment had UCVA $\leq 20 / 40$. *Variables with $\mathrm{P}<0.20$ in the simple regressions were included in the multiple regression. 38 ( $8.43 \%$ ) participants had missing data.

The predictors of presbyopic spectacle wear in this cohort included high school education or above (OR 1.89; 95\% CI 1.06, 3.39; $p=0.031$ ) and worse uncorrected bilateral NVA (<20/63, OR 6.32; 95\% CI 1.86, 21.4; $p=0.003)$ after adjusting for age, monthly income. (Table 4)

Table 4: Logistic regression model of potential predictors of presbyopic spectacle wear among 781 participants completing questionnaires

\begin{tabular}{|c|c|c|c|c|}
\hline \multirow[b]{2}{*}{ Variables } & \multicolumn{2}{|c|}{ Simple logistic regression } & \multicolumn{2}{|c|}{$\begin{array}{l}\text { Multiple logistic regression } \\
\qquad(\mathrm{N}=752)^{*}\end{array}$} \\
\hline & OR (95\% CI) & $\begin{array}{l}\text { P- } \\
\text { value }\end{array}$ & OR (95\% CI) & $\begin{array}{c}\text { P- } \\
\text { value }\end{array}$ \\
\hline Age (y) & $0.97(0.94,0.99)$ & 0.005 & $0.97(0.94,0.99)$ & 0.01 \\
\hline Female sex & $0.85(0.51,1.40)$ & 0.52 & & \\
\hline \multicolumn{5}{|l|}{ Education } \\
\hline Less than high school & Reference & & Reference & \\
\hline High school or above & $2.37(1.42,3.95)$ & 0.001 & $1.89(1.06,3.39)$ & 0.031 \\
\hline \multicolumn{5}{|l|}{ Monthly income, US\$ } \\
\hline$<300$ & Reference & & Reference & \\
\hline$\geq 300$ to $<600$ & $1.12(0.60,2.08)$ & 0.73 & $1.27(0.65,2.47)$ & 0.49 \\
\hline
\end{tabular}

This article is protected by copyright. All rights reserved. 


\begin{tabular}{|c|c|c|c|c|}
\hline$\geq 600$ to $<900$ & $1.44(0.59,3.54)$ & 0.43 & $1.53(0.57,4.13)$ & 0.40 \\
\hline$\geq 900$ & $2.16(0.69,6.76)$ & 0.19 & $1.91(0.55,6.58)$ & 0.31 \\
\hline Own smart phone & $2.09(1.23,3.57)$ & 0.007 & $0.65(0.35,1.21)$ & 0.18 \\
\hline \multicolumn{5}{|c|}{$\begin{array}{l}\text { Hours of smart phone use } \\
\text { per day }\end{array}$} \\
\hline$\leq 1$ & Reference & & & \\
\hline$>1$ to $\leq 3$ & $1.14(0.42,3.05)$ & 0.80 & & \\
\hline$>3$ & $3.48(0.45,27.2)$ & 0.23 & & \\
\hline
\end{tabular}

\section{Uncorrected bilateral near} visual acuity

$>20 / 40$

Reference

Reference

$>20 / 63$ to $\leq 20 / 40$

$1.16(0.37,3.64)$

0.81

$1.94(0.58,6.50)$

0.283

$\leq 20 / 63$

$2.68(0.87,8.24)$

0.09

$6.32(1.86,21.4) \quad 0.003$

*Variables with $\mathrm{P}<0.20$ in the simple regressions were included in the multiple regression. 29 (3.71\%) subjects had missing data.

\section{DISCUSSION}

We found that over half (54.9\%) of this population sample of urban Chinese residents owned smartphones, and that over two-thirds (68.1\%) of those with CNVI reported some difficulty in smartphone usage. Those with higher education levels were more likely to report such difficulties, and nearly $40 \%$ were interested in mobile phone features to address these problems, among whom three-quarters would pay for them, a median of US\$45. Uncorrected presbyopia has a significant influence on ease of smartphone use in this middle-income country setting, affecting a substantial proportion 
of even educated urban-dwellers. The high willingness to pay suggests that the market for technical solutions may be substantial.

This is the first population study of presbyopia influence on smartphone use of which we are aware. The design offers certain key advantages, as a clinic-based approach would be more likely to enrol participants already having contact with the medical care system, and might thus tend to over-estimate the proportion of persons having access to presbyopic correction. Nonetheless, ownership was relatively high $(66.2 \%)$ in this setting, compared to a previous study in China $(51.5 \%),{ }^{6}$ likely due to the current study's setting in a relatively wealthy urban area, as compared to the previous, ruralbased study. Our finding that CNVI led to significant difficulties with mobile phone use is consistent with a previous, non-population study from Zanzibar. ${ }^{12}$

We found that more educated participants were more likely to report difficulties in utilizing smartphones, even adjusting for daily use time and level of NVA. It may be that more educated users are using their smartphones for more visually-demanding tasks (web searches vs games, for example). Three quarters (73.7\%) of participants having difficulty with smartphone use in the current study reported using presbyopic glasses as their coping strategy, the most commonly-reported strategy. However, the fact that difficulties were reported suggests that glasses were not an entirely satisfactory solution. Problems with quality and accuracy of routinely-available presbyopic spectacles have previously been identified in China, ${ }^{6}$ and this may explain the failure of spectacles to fully address problems with smartphone use. Alternatively, respondents may simply have found presbyopic glasses inconvenient to use in conjunction with their smartphones. Nonetheless, there does seem to be ample room for technological solutions beyond those already offered by available devices, such as adjustment in the size of type face. Potential solutions might include the ability to project images from the smartphone screen onto a conveniently-located surface at an appropriate reading 
distance, or directly onto the retina of the user, as with devices such as the GuytonMinkowski Potential Acuity Meter. ${ }^{20}$

Strengths of the current study include the population-based sampling and relatively high response rate (83.5\%), and careful assessment of CNVI using a well-described and validated protocol. ${ }^{4}$ Unlike most previous studies touching on presbyopia and smartphone use, the current report concentrates entirely on smartphones and mobile phones, and thus contains more information about problems with their use and possible solutions to these problems.

Limitations must also be acknowledged. Rates of participation at this round of examination were $<70 \%$. Participants who underwent examination in the baseline study from which this cohort was drawn were more likely to be female, older and possibly had more visual problems. Additionally, those who did not complete the questionnaire in the current study had a higher level of education, which was a predictor of difficulty using smartphones and of spectacle wear among those with CNVI. Difficulty in using smartphones in this age group is a significant problem, and is likely to increase in prominence given the increasing popularity of and reliance on smartphones, and the aging of the Chinese and global populations. Ample demand exists in this middle-income country setting for novel solutions to improve ease of smartphone use in the face of presbyopia, the world's most common cause of vision impairment. 


\section{REFERENCES}

1. Bourne RR, Flaxman SR, Braithwaite T, et al. Magnitude, temporal trends, and projections of the global prevalence of blindness and distance and near vision impairment: a systematic review and meta-analysis. Lancet Glob Health 2017; 5: e88897.

2. Frick KD, Joy SM, Wilson DA, et al. The Global Burden of Potential Productivity Loss from Uncorrected Presbyopia. Am J Ophthalmol. 2015; 122: 1706-10

3. Holden BA, Fricke TR, Ho SM, et al. Global Vision Impairment Due to Uncorrected Presbyopia. Arch Ophthalmol. 2008; 126: 1731-39

4. He M, Abdou A, Naidoo KS, et al. Prevalence and Correction of Near Vision Impairment at Seven Sites in China, India, Nepal, Niger, South Africa, and the United States. Am J Ophthalmol. 2012; 154:107-16

5. Khanna RC, Rao GN. Presbyopia and the Sustainable Development Goals. Lancet Glob Health. Published Online, doi: 10.1016/S2214-109X(18)30355-3.

6. Lu Q, He W, Murthy GV, et al. Presbyopia and near-vision impairment in rural northern China. Invest Ophthalmol Vis Sci 2011; 52: 2300-05

7. Lu Q, Congdon N, He X, et al. Quality of Life and Near Vision Impairment Due to Functional Presbyopia among Rural Chinese Adults. Invest Ophthalmol Vis Sci 2011; 52: 4118-23

8. Patel I, Munoz B, Burke AG, et al. Impact of presbyopia on quality of life in a rural African setting. Ophthalmol. 2006; 113: 728-34

9. Bekibele CO, Gureje O. Impact of self-reported visual impairment on quality of life in the Ibadan study of ageing. Br J Ophthalmol. 2007; 92: 612-5 
10. Muhammad N, Alhassan MB, Umar MM. Visual function and vision-related quality of life in presbyopic adult population of Northwestern Nigeria. Niger Med J. 2015; 56: 31722

11. Nirmalan PK, Krishnaiah S, Shamanna BR, et al. A population-based assessment of presbyopia in the state of Andhra Pradesh, south India: the Andhra Pradesh Eye Disease Study. Invest Ophthalmol Vis Sci. 2006; 47: 2324-28

12. Laviers HR, Omar $F$, Jecha $H$, et al. Presbyopic spectacle coverage, willingness to pay for near correction, and the impact of correcting uncorrected presbyopia in adults in Zanzibar, East Africa. Invest Ophthalmol Vis Sci. 2010; 51: 1234-41

13. Sherwin JC, Keeffe JE, Kuper $\mathrm{H}$,et al . Functional presbyopia in a rural Kenyan population: the unmet presbyopic need. Clin Exp Ophthalmol. 2008; 36: 245-51 14. du Toit R, Palagyi A, Ranke J, et al. The Impact of Reduced Distance and Near Vision on the Quality of Life of Adults in Timor-Leste. Ophthalmol. 2010; 117: 2308-14 15. Reddy PA, Congdon N, MacKenzie G, et al. Effect of providing near glasses on productivity among rural Indian tea workers with presbyopia (PROSPER): a randomised trial. Lancet Glob Health. Published Online, doi: 10.1016/S2214109X(18)30329-2

16. International Telecommunication Union, World Telecommunication (2017) Mobilecellular telephone subscriptions per 100 inhabitants. Accessed March 2017. Available from: http://data.worldbank.org/indicator/IT.CEL.SETS.P2

17. Carson S, Furuskär A, Jonsson P, et al. (2017) Ericsson Mobility Report. Accessed March 2017. Available from: https://www.ericsson.com/mobility-report

18. Williams S, Brian G, du Toit R. Measuring Vision-specific Quality of Life among Adults in Fiji. Ophthalmic Epidemiol. 2012; 19: 388-95 
19. He M, Abdou A, Ellwein LB, et al. Age-related prevalence and met need for correctable and uncorrectable near vision impairment in a multi-country study. Ophthalmology. 2014; 121: 417-22

20. Waltuck MH. Mentor Guyton-Minkowski potential acuity meter. Ophthalmic Surgery. 1994; 25: 576-9.

21. Han X, Ellwein LB, Guo X. et al. Progression of Near Vision Loss and Incidence of Near Vision Impairment in an Adult Chinese Population. Ophthalmology. 2017; 124(5): 734-742. 

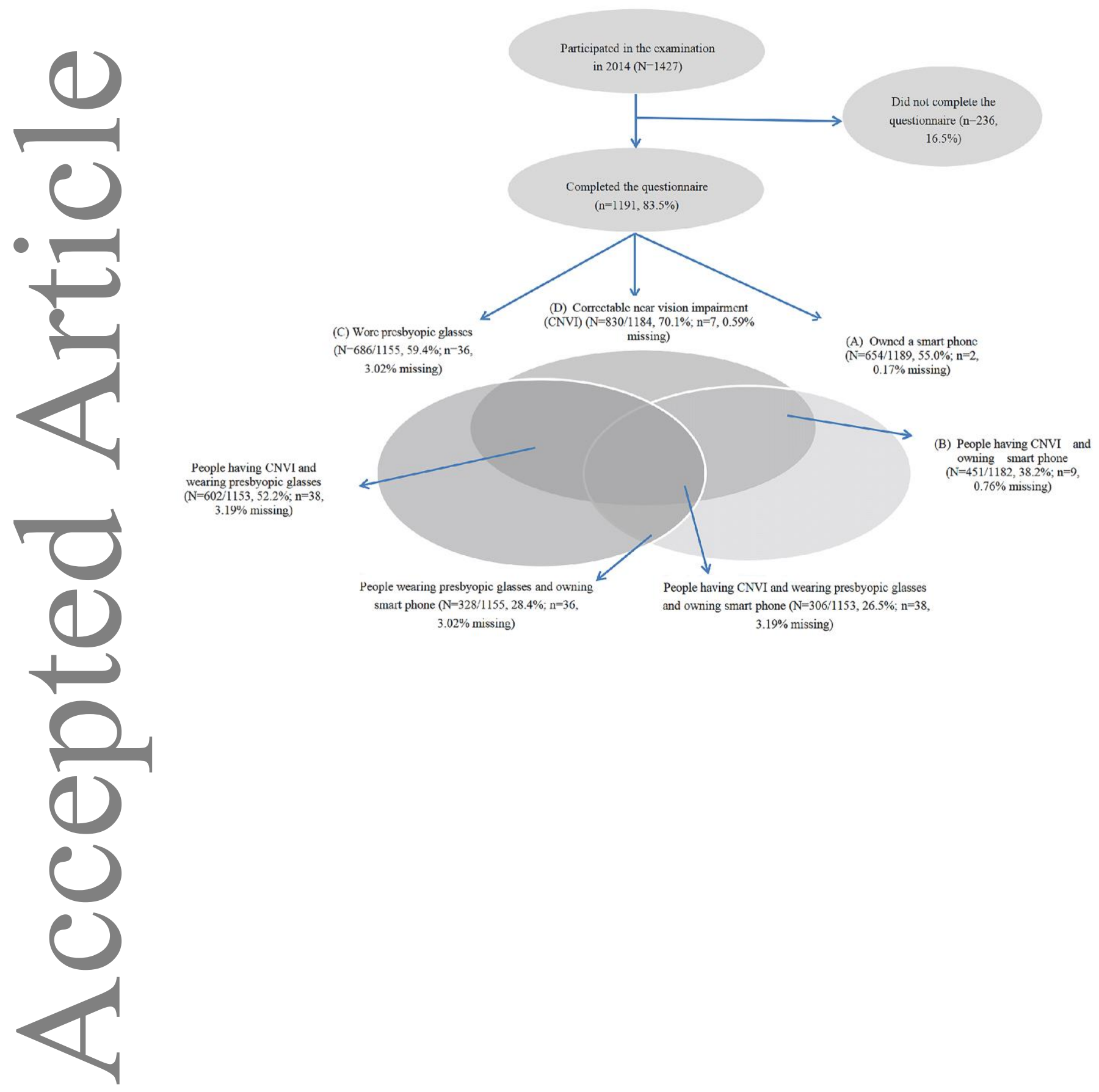

This article is protected by copyright. All rights reserved 